УДК 615.32:547.9+543.544

\title{
НОВЫЕ ПОДХОДЫ К СТАНДАРТИЗАЦИИ ЛИСТЬЕВ СЕННЫ
}

\author{
() В.А. Куркин ${ }^{*}$ А.А. Шмыгарева \\ Самарский государственный медицинский университет, ул. Чапаевская, 89, \\ Самара, 443099 (Россия), e-mail: Kurkinvladimir@yandex.ru
}

Обоснована целесообразность использования для определения подлинности листьев сенны, или кассии остролистной (Cassia acutifolia Del.) метода тонкослойной хроматографии и спектрофотометрии. В результате химического исследования листьев кассии остролистной выделены доминирующие компоненты данного растения - 1,7-дигидрокси-3-карбоксиантрахинон, 8-O- $\beta$-D-глюкопиранозид торахризона, кемпферол-3-О-гентиобиозид - и на этой основе разработаны методологические подходы к стандартизации сырья, заключающиеся в определении не только антраценпроизводных, но и других диагностических фенольных веществ, включая флавоноиды и производные нафталина. Разработана концепция методики количественного определения суммы антраценпроизводных с использованием спектрофотометрии при аналитической длине волны 530 нм. Содержание суммы антраценпроизводных в образцах сырья варьирует от 1,21 до $1,88 \%$ (в пересчете на сеннозид В).

Ключевые слова: Cassia acutifolia Del., кассия остролистная, антраценпроизводные, флавоноиды, производные нафталина, стандартизация. спектрофотометрия, ТСX.

\section{Введение}

Одной из самых широко используемых групп лекарственных препаратов, применяемых в коррекции функциональных нарушений деятельности пищеварительной системы, являются слабительные средства [1]. В медицинской практике широко применяются лекарственные препараты на основе растительного сырья, содержащего антраценпроизводные [2-4], причем наиболее популярным источником являются два вида кассии (сенна) - кассия остролистная (Cassia acutifolia Del.), или сенна александрийская (Senna alexandrina Mill.) и кассия узколистная (Cassia angustifolia Vahl.).

Одной из противоречивых проблем с точки зрения фармакопейного анализа является стандартизация сырья кассии. Так, фармакопейная статья на листья кассии (ГФ СССР издания ХІ) включает раздел «Качественные реакции», однако он не предусматривает применение тонкослойной хроматографии ТСХ [5]. В этом отношении имеется зарубежный опыт применения ТСХ, однако, на наш взгляд, его тоже нельзя признать удачным. Дело в том, что в этом случае для определения подлинности сырья используется в качестве стандарта экстракт сенны, что не позволяет проводить интерпретацию результатов с точки зрения конкретных значений $\mathrm{R}_{\mathrm{f}}$ для диагностических веществ.

Методика количественного определения суммы антраценпроизводных в листьях кассии [5], включенная в раздел «Количественное определение» фармакопейной статьи на данное сырье, также имеет ряд недостатков: является громоздкой, многостадийной и небезопасной, включающей такие стадии, как кислотный гидролиз, многократная экстракция сырья, обработка диэтиловым эфиром - легкокипящим огне-

Куркин Владимир Александрович - заведующий кафедрой фармакогнозии с ботаникой и основами фитотерапии, доктор фармацевтических наук, профессор, тел.: (846) 260-33-59, e-mail: Kurkinvladimir@yandex.ru Шмыгарева Анна Анатольевна - доцент кафедры фармации, кандидат фармацевтических наук, e-mail: a.shmygareva@mail.ru опасным растворителем. Кроме того, в методике используется фотоэлектроколориметрия, предусматривающая измерение оптической плотности при аналитической длине волны при 523 нм, а расчет содержания суммы производных антрацена осуществляется с использованием построе-

\footnotetext{
* Автор, с которым следует вести переписку.
} 
ния громоздкого калибровочного графика раствора кобальта хлорида в пересчете на хризофановую кислоту. Методики количественного определения антраценпроизводных, включенные в зарубежные фармакопеи, с точки зрения пробоподготовки сопоставимы с ГФ СССР издания ХІ и отличаются только значением используемой аналитической длиной волны (515 нм вместо 523 нм) и подходом, предусматривающим расчет содержания на сеннозид В [6,7]. Целесообразность внедрения новых современных методов анализа связана еще и с тем, что в существующих подходах к анализу не в полной мере используется все разнообразие химического состава сырья кассии [8-11].

На наш взгляд, актуальным является также учет значимости флавоноидов [9], главным образом производных кемпферола, как по содержанию, так и по возможному вкладу в фармакологическое действие препаратов на основе кассии. Кроме того, представляется возможным вклад в слабительный эффект препаратов кассии и производных нафталина, в частности, 8-O- $\beta$-D-глюкопиранозида торахризона.

Цель настоящего исследования - разработка методических и методологических подходов к стандартизации сырья сенны.

\section{Экспериментальная часть}

Объектами исследования служили промышленные образцы листьев сенны (ОАО «Красногорсклексредства», ООО «ФитоСтарт», ООО «СТ-Медифарм», ООО «Алтайский кедр»).

Препаративное выделение веществ осуществляли из листьев производства ОАО «Красногорсклексредства» с использованием колоночной хроматографии.

Воздушно-сухое сырье (100 г) подвергали исчерпывающему экстрагированию $70 \%$ этиловым спиртом, сочетая при этом способ мацерации (24 ч) с последующей экстракцией при температуре $85-90{ }^{\circ} \mathrm{C}$. Водно-спиртовые экстракты упаривали под вакуумом до густого остатка (около 30 мл). Сгущенный экстракт высушивали на 50 г силикагеля L 40/100 (выход экстрактивных веществ - 19,55\%) и полученный порошок (экстракт + силикагель) наносили на слой силикагеля (100 г), сформированный в хлороформе. Хроматографическую колонку элюировали хлороформом и смесью хлороформ-этиловый спирт в различных соотношениях (99:1; $97: 2 ; 97: 3 ; 95: 5 ; 93: 7 ; 90: 10 ; 85: 15 ; 80: 20 ; 70: 30,60: 40,50: 50)$, объем отбираемых фракций - 100 мл. Контроль за разделением веществ осуществляли с помощью ТСХ-анализа на пластинках «Сорбфил ПТСХ-АФ-А-УФ» в системах хлороформ-этанол (9: 1), хлороформ - метанол вода (26: $14: 3)$, а также $н$-бутанол-ледяная уксусная кислота-вода (4: $1: 2)$. Детекцию веществ на хроматограммах осуществляли просмотром их в УФ-свете (хроматоскоп) при длине волны 254 нм и 366 нм, а также проявлением щелочным раствором диазобензолсульфокислоты (фенольные соединения) и спиртовым раствором алюминия хлорида (флавоноиды) с последующим нагреванием пластинок при температуре 100-105 ${ }^{\circ} \mathrm{C}$. Фракции, содержащие вещества 1-3, с целью их выделения подвергали рехроматографированию на колонке с силикагелем L 40/100 (соотношение вещества и сорбента - 1 : 20) с использованием смеси хлороформ - этиловый спирт в градиентном режиме. Окончательную очистку вещества 3 осуществляли рехроматографией на колонке с полиамидом «Woelm» (Германия) (соотношение вещества и сорбента 1: 20), элюируя смесями воды и этилового спирта в различных соотношениях, а затем водным раствором гидрокарбоната натрия с последующим осаждением целевого соединения из элюата подкислением $10 \%$ раствором хлороводородной кислоты до слабокислой среды (рН около 6,0).

Спектры ЯМР ${ }^{1}$ Н получали на приборах «Bruker АM 300» (300 МГц) (США), масс-спектры снимали на масс-спектрометре «Kratos MS-30» (Япония), регистрацию УФ-спектров проводили с помощью спектрофотометра «Specord 40» (Analytik Jena, Германия).

В ходе разработки подходов стандартизации суммы антраценпроизводных в листьях кассии изучены УФ-спектры водно-спиртовых извлечений из изучаемых образцов растительного сырья.

Для разработки методики качественного анализа сырья кассии использовали ТСХ (пластинки «Сорбфил ПТСХ-АФ-А-УФ»; система растворителей: хлороформ - этиловый спирт - вода в соотношении $26: 16: 3$ ). Анализируемые пробы (водно-спиртовое извлечение из листьев сенны александрийской) и 0,1\% спиртовые растворы выделенных соединений (1-3) наносили на хроматографические пластинки микропипеткой в объеме 0,02 мл. Результаты оценивались при просмотре хроматограмм в УФ-свете при длине волны 254 и 366 нм, а также после проявления щелочным раствором диазобензолсульфокислоты.

В результате фитохимического исследования компонентного состава листьев кассии выделены три доминирующих вещества - 8-O- $\beta$-D-глюкопиранозид торахризона (1), кемпферол-3-О-гентиобиозид (2) и 1,7-дигидрокси-3-карбоксиантрахинон (3) (рис. 1). 
<smiles>CC(=O)c1c(C)cc2cccc(OC3OC(CO)C(O)C(O)C(O)C3O)c2c1O</smiles>

8-O- $\beta$-D-глюкопиранозид торахризона (1)<smiles>O=C(O)c1cc(O)c2c(c1)C(=O)c1ccc(O)cc1C2=O</smiles>

1,7-Дигидрокси-3-карбоксиантрахинон (3)<smiles></smiles>

Кемпферол-3-О-гентиобиозид (2)

Реин (4)

8-O-ß-D-глюкопиранозид торахризона (1,8-дигидрокси-6-метокси-2-ацетил-3-метилнафталин) (1) Аморфное вещество светло-желтого цвета состава $\mathrm{C}_{20} \mathrm{H}_{24} \mathrm{O}_{10}$. Масс-спектр $\left(70 \mathrm{eV}, 200{ }^{\circ} \mathrm{C}, \mathrm{m} / \mathrm{z}, \%\right): \mathrm{M}^{+} 408$ (18\%), $\mathrm{M}^{+}$агликона 246 (82\%), $\mathrm{M}^{+}$агликона - $\mathrm{CH}_{3} 231$ (100\%), 217 (28\%). УФ-спектр (ЕtOH, $\left.\lambda_{\max }, \mathrm{HM}\right): 241$, 266 пл, 332 пл, 344 нм. ${ }^{1}$ Н-ЯМР спектр (300 МГц, ДМСО-d 6 , $\delta$, м.д., Ј/Гц): 9,58 (1Н, с, ОН-группа при С-1), 7,06 (1H, с, Н-4), 6,92 (1Н, д, J = 2, Н-7), 6,70 (1Н, д, J = 2, Н-5), 5,03 (1Н, д, J = 7, Н-1 ${ }^{1}$ глюкопиранозы), 3,1-4,5 (6Н глюкопиранозы), 4,30 (3Н, с, ароматическая $\mathrm{OCH}_{3}$-группа при С-6), 2,53 (3Н, с, $\mathrm{COCH}_{3}$ при С-2), 2,25 (3Н, с, ароматическая $\mathrm{CH}_{3}$ при С-3).

Кемпферол-3-О-гентиобиозид (3-О-гентиобиозид 3,5,7,4 ${ }^{1}$-тетрагидроксифлавона) (2). Светложелтое кристаллическое вещество состава $\mathrm{C}_{27} \mathrm{H}_{30} \mathrm{O}_{16}$ с т.пл. 174-177 ${ }^{\circ} \mathrm{C}$ (водный спирт). Масс-спектр $\left(70 \mathrm{eV}, 200{ }^{\circ} \mathrm{C}, \mathrm{m} / \mathrm{z}, \%\right): 286\left(\mathrm{M}^{+}\right.$агликона, 100\%), 153 (15), 121 (22). УФ-спектр (ЕtOH, $\left.\lambda_{\max }, \mathrm{Hм}\right): 269$, $350 \mathrm{Hм} ;+\mathrm{NaOAc} 274,368 \mathrm{нм} ;+\mathrm{NaOAc}+\mathrm{H}_{3} \mathrm{BO}_{3} 272,355 \mathrm{нм} ;+\mathrm{A} 1 \mathrm{Cl}_{3}$ и $+\mathrm{A} 1 \mathrm{C1}_{3}+\mathrm{HCl} 275,305,395 \mathrm{нм} .{ }^{1} \mathrm{H}-$ ЯМР-спектр (300 МГц, ДМСО-d 6 , $\delta$, м.д., Ј/Гц): 12,58 (1Н, с, 5-ОН), 8,03 (2H, д, J = 9 Гц, Н-2 $\left.{ }^{1} 6^{1}\right), 6,87$ (2H, д, J = 9 Гц, Н-3 $\left.{ }^{1} 5^{1}\right), 6,42$ (1Н, д, J = 2,5 Гц, Н-8), 6,20 (1Н, д, J = 2,5 Гц, Н-6), 5,35 (1Н, д, 7 Гц, Н- $1^{11}$ глюкозы), 4,03 (1Н, д, J = 7 Гц, Н-1 ${ }^{111}$ глюкозы), 3,10-5,2 (м, 12Н глюкозы).

1,7-дигидрокси-3-карбоксиантрахинон (3). Кристаллы оранжевого цвета состава $\mathrm{C}_{15} \mathrm{H}_{8} \mathrm{O}_{6}$, массспектр (70 eV, $\left.200{ }^{\circ} \mathrm{C}, \mathrm{m} / \mathrm{z}, \%\right): \mathrm{M}^{+} 284$ (100\%), 256 (7), 254 (26), 239 (32), т. пл. 305-308 ${ }^{\circ} \mathrm{C}$ (водный спирт). УФ-спектр (ЕtOH, $\lambda_{\max }$, нм): 234, 264, 433 нм. ${ }^{1}$ Н-ЯМР спектр (300 МГц, ДМСО-d 6 , $\delta$, м.д., Ј/Гц): 11,91 (1Н, c, ОН-группа при С-1), 8,16 (1Н, уш. с, Н-2), 7,85 (1Н, д, J = 9 Гц, Н-6), 7,80 (1Н, уш. с, Н-4), 7,78 (1Н, д, J = 1 Гц, Н-8), 7,42 (1Н, д, J = 9 Гц, Н-5).

С использованием ТСХ обнаружено (рис. 2), что именно соединения 1-3 являются доминирующими компонентами листьев сенны. На наш взгляд, обнаружение методом ТСХ соединений 1-3, диагностически значимых для листьев сенны, является перспективным подходом в плане идентификации сырья и препаратов данного растения. Это тем более важно, что в силу невысокого содержания сеннозида А и В в листьях кассии [9] определение данных соединений методом ТСХ весьма проблематично. Этот вывод согласуется с результатами исследований зарубежных ученых [10], в соответствии с которыми доминирующим антраценпроизводным листьев кассии является реин (4). При этом обращает на себя внимание тот факт, что, по нашим данным, доминирующим антраценпроизводным соединением листьев кассии является не реин (4), а близкий к нему по хроматографической подвижности, физико-химическим и спектральным характеристикам 1,7-дигидрокси-3-карбоксиантрахинон (3). Этот вывод сделан на основании данных ЯМР-спектра 
1,7-дигидрокси-3-карбоксиантрахинона (3): наличие при 11,91 м.д. одного уширенного синглетного сигнала, принадлежащего 1-ОН-группе, в сочетании с характером сигналов ароматических протонов при С-5, С-6 и С-8. По литературным данным в ЯМР-спектре реина характерными являются два синглетных сигнала в области 12,0 м.д. и 11,9 м.д. 1-ОН-группы и 8-ОН-группы [12].

К доминирующим фенольным компонентам относятся также 8-O- $\beta$-D-глюкопиранозид торахризона (1) и кемпферол-3-О-гентиобиозид (2) (рис. 2), которые, на наш взгляд, имеют диагностическое значение в плане идентификации сырья кассии. Интересно, что, по данным зарубежных ученых, и в условиях ВЭЖХ кемпферол-3-О-гентиобиозид (2) является доминирующим соединением [9].

Большой интерес с точки зрения стандартизации представляет тот факт, что характер кривой поглощения электронного спектра водно-спиртового извлечения из листьев кассии остролистной $\left(\lambda_{\max }\right.$ около 270 и 350 нм) в основном определяется флавоноидами, в частности, 3-О-гентиобиозидом кемпферола (рис. 3).

Диагностическое значение имеет также кривая поглощения щелочно-аммиачного раствора водноспиртового извлечения из листьев кассии (испытуемый раствор в методике количественного определения): максимум поглощения при 430 нм \pm 3 нм (антраценпроизводные) (рис. 4).
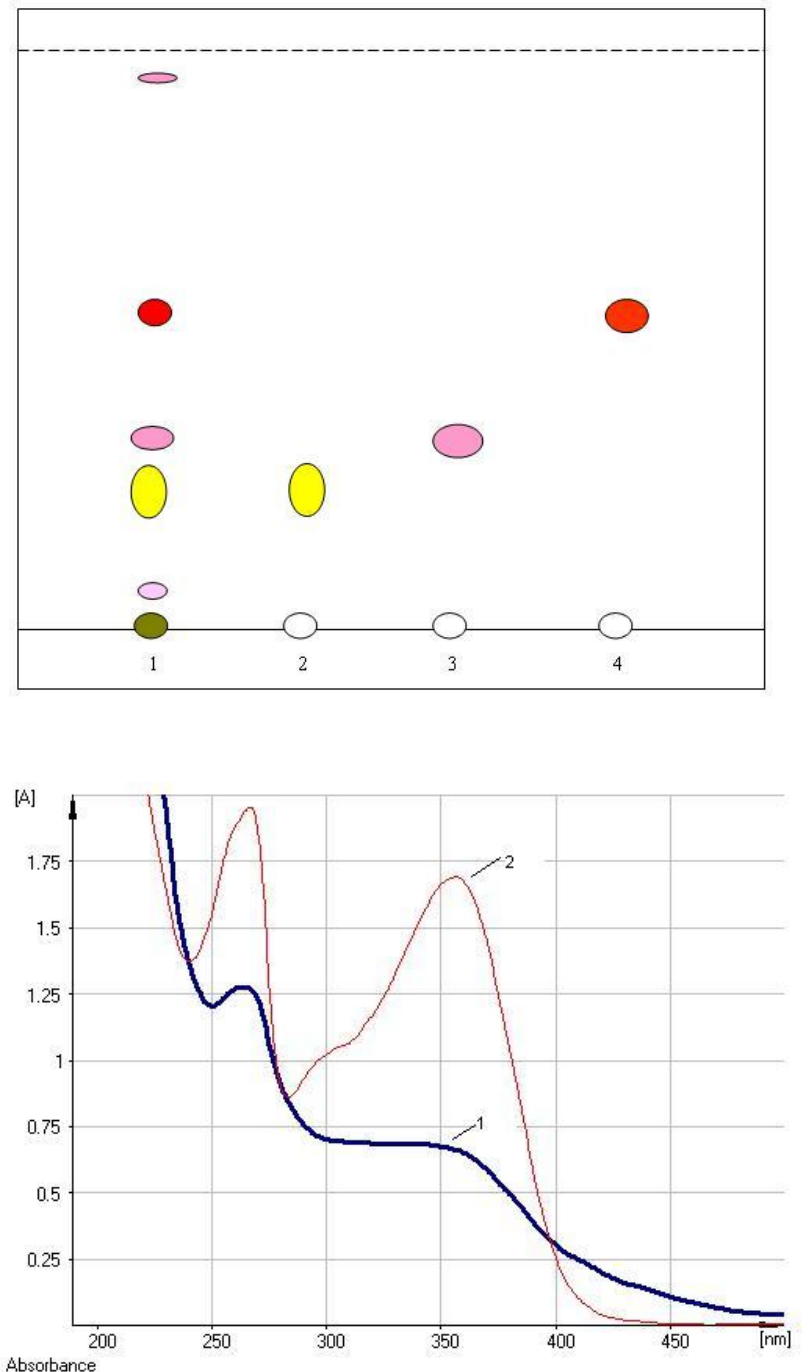

Рис. 3. Электронные спектры водно-спиртового извлечения из листьев кассии остролистной: 1 - исходный раствор водно-спиртового извлечения из листьев кассии остролистной; 2 - раствор 3-Огентиобиозида кемпферола
Рис. 2. Хроматографический профиль водноспиртового извлечения из сырья кассии остролистной: 1 - водно-спиртовое извлечение из листьев кассии остролистной; 2 - раствор кемпферола-3-О-гентиобиозида (2); 3 - раствор 1,7-дигидрокси-3-карбоксиантрахинона (3); 4 - раствор торахризона-8-О-глюкозида (1)

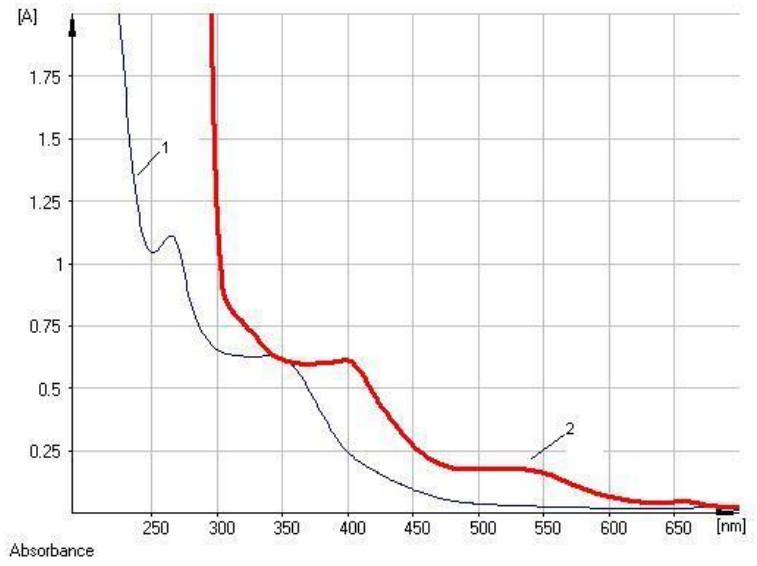

Рис. 4. Электронные спектры исходного раствора (1) и щелочно-аммиачного раствора водноспиртового извлечения из листьев кассии (2) 
С целью разработки проекта методики количественного определения суммы антраценпроизводных определены оптимальные условия экстракции антраценпроизводных из листьев кассии: экстрагент - 70\% этиловый спирт; соотношение «сырье - экстрагент» - $1: 30$; время экстракции - извлечение на кипящей водяной бане в течение 60 мин (табл. 1). В качестве аналитической длины волны рекомендовано значение 530 нм, хотя в настоящее время для целей стандартизации используются и другие значения длины волны [5-8].

В соответствии с Европейской фармакопеей для расчета содержания суммы антраценпроизводных целесообразно использовать теоретическое значение удельного показателя поглощения (240) стандартного образца сеннозида В [6].

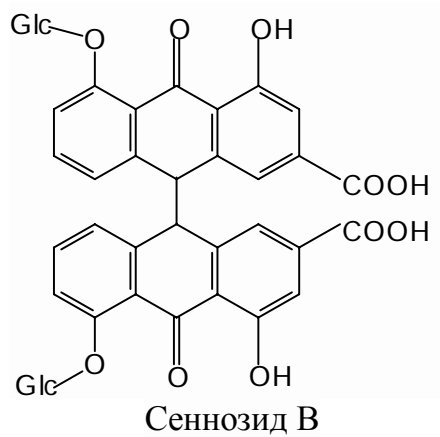

Таблица 1. Влияние различных факторов на полноту извлечения антраценпроизводных из листьев кассии остролистной

\begin{tabular}{c|c|c|c}
\hline $\begin{array}{c}\text { Концентрация } \\
\text { этилового спирта, \% }\end{array}$ & $\begin{array}{c}\text { Соотношение } \\
\text { «сырье - экстрагент» }\end{array}$ & $\begin{array}{c}\text { Время экстракции, } \\
\text { мин }\end{array}$ & $\begin{array}{c}\text { Содержание суммы антраценпроизвод- } \\
\text { ных в пересчете на сеннозид В и а.с.с., \% }\end{array}$ \\
\hline 40 & $1: 30$ & 60 & $1,49 \pm 0,02$ \\
50 & $1: 30$ & 60 & $1,50 \pm 0,02$ \\
60 & $1: 30$ & 60 & $1,78 \pm 0,03$ \\
60 & $1: 50$ & 60 & $1,86 \pm 0,04$ \\
70 & $1: 30$ & 30 & $1,52 \pm 0,02$ \\
70 & $1: 30$ & 45 & $1,62 \pm 0,03$ \\
70 & $1: 30$ & 60 & $1,87 \pm 0,02$ \\
70 & $1: 30$ & 90 & $1,81 \pm 0,02$ \\
70 & $1: 30$ & 120 & $1,48 \pm 0,02$ \\
70 & $1: 50$ & 60 & $1,88 \pm 0,03$ \\
70 & $1: 100$ & 60 & $1,87 \pm 0,04$ \\
90 & $1: 30$ & 60 & $1,70 \pm 0,03$ \\
95 & $1: 30$ & 60 & $1,44 \pm 0,02$ \\
\hline
\end{tabular}

Концепция методики количественного определения суммы антраценпроизводных в листьях кассии остролистной. Аналитическую пробу сырья измельчают до размера частиц, проходящих сквозь сито с отверстиями диаметром 1 мм. Около 1 г измельченного сырья (точная навеска) помещают в колбу со шлифом вместимостью 100 мл, прибавляют 30 мл 70\% этилового спирта. Колбу закрывают пробкой и взвешивают на тарированных весах с точностью до $\pm 0,01$ г. Колбу присоединяют к обратному холодильнику и нагревают при температуре водяной бани в течение 60 мин. Затем охлаждают в течение 30 мин, закрывают той же пробкой, снова взвешивают, восполняют недостающий экстрагент до первоначальной массы и извлечение фильтруют.

Испытуемый раствор А готовят следующим образом: 1 мл фильтрата помещают в колбу вместимостью 25 мл и доводят объем раствора до метки щелочно-аммиачным раствором, приготовленным по фармакопейной методике [5]. Испытуемый раствор А помещают в колбу емкостью 25 мл и нагревают в течение 15 мин на кипящей водяной бане с обратным холодильником. После охлаждения измеряют оптическую плотность испытуемого раствора на спектрофотометре при длине волны 530 нм. В качестве раствора сравнения используют воду очищенную.

Содержание суммы антраценпроизводных в листьях сенны обыкновенной в пересчете на сеннозид В и абсолютно сухое сырье в процентах $(\mathrm{X})$ рассчитывают по формуле

$$
X=\frac{A \cdot 25 \cdot 30 \cdot 100}{m \cdot 240 \cdot(100-W)}
$$

где $A$ - оптическая плотность испытуемого раствора; $m$ - масса сырья, г; 240 - удельный показатель поглощения (Е 1\% $)$ сеннозида В при 530 нм; $W$ - потеря в массе при высушивании, в процентах.

С использованием разработанной методики проанализирован ряд промышленных образцов листьев сенны и показано, что содержание суммы антраценпроизводных в образцах сырья варьирует в пределах от 1,21 до 1,88\% (в пересчете на сеннозид В) (табл. 2). 
Таблица 2. Содержание суммы антраценпроизводных в различных образцах сырья кассии остролистной

\begin{tabular}{l|c}
\hline \multicolumn{1}{c|}{ Характеристика образца сырья } & $\begin{array}{c}\text { Содержание суммы антраценпроизводных } \\
\text { в пересчете на а.с.с. и сеннозид В, \% }\end{array}$ \\
\hline Сенны листья в фильтр-пакетах (ОАО «Красногорсклексредства») & $1,56 \pm 0,02$ \\
Сенны листья (ОАО «Красногорсклексредства») & $1,88 \pm 0,02$ \\
Сенны листья (ООО «СТ-Медифарм») & $1,86 \pm 0,03$ \\
Сенны листья (ООО «ФитоСтарт» & $1,21 \pm 0,02$ \\
Фиточай в фильтр-пакетах (ООО «Алтайский кедр») & $1,40 \pm 0,03$ \\
\hline
\end{tabular}

Метрологические характеристики методики количественного определения содержания суммы антраценпроизводных в сырье кассии остролистной представлены в таблице 3. Результаты статистической обработки проведенных опытов свидетельствуют о том, что ошибка единичного определения суммы антраценпроизводных в сырье кассии остролистной с доверительной вероятностью $95 \%$ составляет $\pm 3,27 \%$ (табл. 3).

Таким образом, в результате фитохимических исследований листьев кассии разработаны новые подходы к стандартизации сырья кассии, заключающиеся в определении антраценпроизводных (1,7-дигидрокси-3-карбоксиантрахинон), флавоноидов (кемпферол-3-О-гентиобиозид) и производных нафталина (8-O-ß-D-глюкопиранозид торахризона) с использованием ТСХ и спектрофотометрии.

Таблица 3. Метрологические характеристики методики количественного определения суммы антраценпроизводных в сырье кассии остролистной

\begin{tabular}{c|c|c|c|c|c|c}
\hline $\mathrm{f}$ & $\bar{X}$ & $\mathrm{~S}$ & $\mathrm{P}, \%$ & $\mathrm{t}(\mathrm{P}, \mathrm{f})$ & $\Delta \mathrm{X}$ & $\mathrm{E}, \%$ \\
\hline 10 & 1,88 & 0,0276 & 95 & 2,23 & $\pm 0,061$ & $\pm 3,27$ \\
\hline
\end{tabular}

\section{Bbыводы}

1. Из листьев кассии остролистной выделены доминирующие компоненты данного растения - 1,7дигидрокси-3-карбоксиантрахинон (антраценпроизводное соединение), 8-O- $\beta$-D-глюкопиранозид торахризона (производное нафталина) и кемпферол-3-О-гентиобиозид (флавоноид), имеющие диагностическое значение.

2. Разработаны методологические подходы к стандартизации листьев кассии остролистной, заключающиеся в определении антраценпроизводных, флавоноидов и производных нафталина с использованием метода тонкослойной хроматографии и спектрофотометрии.

3. Разработана концепция методики количественного определения суммы антраценпроизводных с использованием спектрофотометрии при аналитической длине волны 530 нм. Содержание суммы антраценпроизводных в образцах сырья варьирует от 1,21 до 1,88\% (в пересчете на сеннозид В).

\section{Список литературь}

1. Государственный реестр лекарственных средств. Официальное издание. М., 2008. Т. 1. 1398 с.

2. Куркин В.А. Фармакогнозия : учебник для студентов фармацевтических вузов (факультетов). 2-е изд., перераб. и доп. Самара, 2007. 1239 с.

3. Куркин В.А. Основы фитотерапии : учебное пособие для студентов фармацевтических вузов. Самара, 2009. $963 \mathrm{c.}$

4. Муравьева Д.А., Самылина И.А., Яковлев Г.П. Фармакогнозия : учебник. М., 2002. 656 с.

5. Государственная фармакопея СССР. Общие методы анализа. Лекарственное растительное сырье. МЗ СССР. 11 изд. М., 1990. Вып. 2. 400 с.

6. European Pharmacopoeia, 2004. 1884 p.

7. British Pharmacopoeia. Volume III. Herbal Drugs and Herbal Drug Preparations. 2009.

8. Dave H., Ledwani L. A review on anthraquinones isolated from Cassia species and their applications // Indian Journal of Natural Products and Resources. 2012. Vol. 3, N3. Pp. 291-319.

9. Demirezer L.O., Karahan1 N., Ucakturk E., Kuruuzum-Uz A., Guvenalp Z., Kazaz C. HPLC Fingerprinting of Sennosides in Laxative Drugs with Isolation of Standard Substances from Some Senna Leaves // Rec. Nat. Prod. 2011. Vol. 5, N4. Pp. 261-270.

10. Sakulpanich A., Gritsanapan W. Determination of Anthraquinone Glycoside Content in Cassia fistula Leaf Extracts for Alternative Source of Laxative Drug // International Journal of Biomedical and Pharmaceutical Sciences. 2009. Vol. 3, N1. Pp. 42-45. 
11. Upadhyay A. Chandel Yo., Nayak P.S., Khan N.A. Sennoside contens in Senna (Cassia angustifolia Vahl.) as influenced by date of leaf picking, packaging material and storage period // Journal of Stored Products and Postharvest Research. 2011. Vol. 2, N5. Pp. 97-103.

12. Liu R., Li A., Sun A. Preparative isolation and purification of hydroxyanthraquinones and cinnamic acid from the Chinese medicinal herb Rheum officinale Bill. by high-speed counter-current chromatography // Journal of Chromatography A. 2004. Vol. 1052. Pp. 217-221.

Поступило в редакииюю 28 августа 2014 2.

После переработки 14 февраля 2016 г.

\section{Kurkin V.A. *, Shmygareva A.A. NEW APPROACHES TO STANDARDIZATION OF CASSIA LEAVES}

Samara State Medical University, Chapaevskaia st., 89, Samara, 443099 (Russia), e-mail: Kurkinvladimir@yandex.ru

The expediency of the using for the determination of identity of Cassia acutifolia Del. leaves of spectrophotometry and TLC was substantiated. As the results of the chemical study of Cassia acutifolia leaves were isolated the predominant components of this plant - 1,7-dihydroxy-3-carboxyanhraquinone, 8-O- $\beta$-D-glucopyranoside of torachrysone, kaempferol-3-Ogentiobioside and on this basis the methodological approaches for standardization of Cassia acutifolia leaves were developed. These methodological approaches consist in the determination not only of anthracenderivatives, but also other diagnostic phenolic compounds, including flavonoids and naphthalenes. The concept of the method of quantitative determination of the total anthracenderivatives by means of spectrophotometry at analytical wavelength $530 \mathrm{~nm}$ was developed. The total anthracenderivatives contents of the in Cassia acutifolia leaves are varied with 1,21 to 1,88\% (calculated on sennoside B).

Keywords: Cassia acutifolia Del., leaves anthracenderivatives, flavonoids, naphthalenes, standardization, spectrophotometry, TLC.

\section{References}

1. Gosudarstvennyi reestr lekarstvennykh sredstv. T. 1. Ofitsial'noe izdanie. [State Register of medicines. Vol. 1. The official publication]. Moscow, 2008, 1398 p. (in Russ.).

2. Kurkin V.A. Farmakognoziia. [Pharmacognosy]. 2 ed. Samara, 2007, 1239 p. (in Russ.).

3. Kurkin V.A. Osnovy fitoterapii. [Basics of phytotherapy]. Samara, 2009, 963 p. (in Russ.).

4. Murav'eva D.A., Samylina I.A., Iakovlev G.P. Farmakognoziia. [Pharmacognosy]. Moscow, 2002, 656 p. (in Russ.).

5. Gosudarstvennaia farmakopeia SSSR. Obshchie metody analiza. Lekarstvennoe rastitel'noe syr'e. [The State Pharmacopoeia of the USSR. General methods of analysis. Medicinal plant material]. 11 ed. Moscow, 1990, issue 2, 400 p. (in Russ.).

6. European Pharmacopoeia, 2004. 1884 p.

7. British Pharmacopoeia. Volume III. Herbal Drugs and Herbal Drug Preparations. 2009.

8. Dave H., Ledwani L. Indian Journal of Natural Products and Resources, 2012, vol. 3, no. 3, pp. 291-319.

9. Demirezer L.O., Karahan1 N., Ucakturk E., Kuruuzum-Uz A., Guvenalp Z., Kazaz C. Rec. Nat. Prod., 2011, vol. 5, no. 4, pp. 261-270.

10. Sakulpanich A., Gritsanapan W. International Journal of Biomedical and Pharmaceutical Sciences, 2009, vol. 3, no. 1 , pp. 42-45.

11. Upadhyay A. Chandel Yo., Nayak P.S., Khan N.A. Journal of Stored Products and Postharvest Research, 2011, vol. 2, no. 5, pp. 97-103.

12. Liu R., Li A., Sun A. Journal of Chromatography A, 2004, vol. 1052, pp. 217-221.

\footnotetext{
* Corresponding author.
} 
